\title{
The Role of Teacher-Child Conflict in Characterizing Early Mother- Child Attachment Influences on Behavior Problems in Preschool
}

\section{Y. FU}

Shanghai Normal University Tianhua College, Shanghai, China

\author{
L. Webster \& R. K. Hackett \\ University of the Pacific, Stockton, CA, US
}

\begin{abstract}
The purpose of the study was to examine the moderating role of teacher-child conflict in characterizing early mother-child attachment influences on behavior problems in preschool. The study used the data from National Institute of Child Health and Human Development's (NICHD) Early child Care Research Network Study of Early Child Care and Youth Development (SECCEY). The results indicated that teacher-child conflict had a statistically significant effect on later behavior problems (both internalizing and externalizing problems) after controlling for the demographic variables, early mother-child attachment behavior and prior behavior problems. However, moderation analyses did not indicate that early mother-child attachment and teacher-child conflict interact together to significantly affect the later behavior problems.
\end{abstract}

KEYWORDS: early mother-child attachment, teacher-child conflict, behavior problems

\section{INTRODUCTION}

The available evidence indicates that not only do teacher-child relationships serve as a protective factor for high-risk children, but positive relationships also facilitate children's development. For example, Buyse, Verschueren and Doumen (2011) found that children with insecure attachments who had high level of teacher-child closeness, were also likely to be rated as being less aggressive [1]. Whether teacher-child conflict is a moderator, just as teacher-child closeness, in linking early mother-child attachment and later behavior problems remains unclear.

The purpose of the current study was to examine the moderating role of teacher-child conflict in the association between early mother-child attachment and behavior problems in preschool. There were two research questions: 1) Is there an effect of teacherchild conflict (54 months) on behavior problems in preschool (54 months), after controlling for the child's gender, mother's education, prior behavior problems, early mother-child attachment and the income-to-needs ratio? 2) Is the relationship between early mother-child attachment (36 months) and behavior problems in preschool (54months) moderated by teacher-child conflict (54months), after controlling for the child's gender, mother's education, prior behavior problems and the incometo-needs ratio?

\section{METHODOLOGY}

\subsection{Sample}

Data from National Institute of Child Health and Human Development Early Child Care Research Network Study of Early Child Care and Youth Development (NICHD SECCYD) were used to investigate the research questions. A total of 715 mothers and children ( 355 boys and 360 girls) were enrolled in the study. $15.2 \%$ of the participants were ethnic minority, and the average mother's education was 14.7 years as compared with $23.6 \%$ and 14.2 years, for the original sample (at one month).

\subsection{Overview of Data Collection}

Mother-child attachment was observed at laboratory visits when children were 36 months old. Teachers completed a teacher-child relationship questionnaire when the children were in preschool at 54 months. Mothers completed a children's behavior problems questionnaire when the children were at 36 and 54 months. Demographic variables included child gender, mother's education, and family SES. Child gender and mother's education were collected from mother interviews during the home visit when the child was one month old. The income-to-needs ratio was an index of family SES, which referred to financial resources per person in the household. This variable was an average income-to-needs ratio of two 
assessments at 36 and 54 months (NICHD ECCRN, 1997) [2].

\subsection{Instruments}

\subsubsection{Child Behavior Checklist (CBCL)}

At 36 months, the study used the 99-item Child Behavior Checklist-2/3 (CBCL; Achenbach, 1992) [3], which included six scales: the social withdrawal, depressed, sleep problems, somatic problems, aggressive, and destructive. The first two belonged to a composite internalizing score, whereas the last two belong to a composite externalizing score. The study used the 118-item CBCL/4-18 at 54 months (Achenbach, 1991)[4]. There were 8 scales. Internalizing problems included withdrawn, somatic complaints, and anxious/depressed, while externalizing problems included delinquent behavior and aggressive behavior (Achenbach, 1991)[4]. Each item had a three-option response, which is from 0 (not true) to 2 (very true or often true). Higher scores indicated more behavior problems.

\subsubsection{A Modified Strange Situation Procedure}

A modified Strange Situation procedure based on recommendations by Cassidy et al. was used to assess attachment patterns at 36 months (Cassidy, \& Marvin, with the MacArthur Attachment Working Group, 1992)[5].The researchers using this assessment were trained by Cassidy or Marvin, the certification acquired is above $75 \%$ agreement. The range of training reliability is from .72 to .85 , or higher. Children's behaviors were classified in four categories: secure attachment, avoidant attachment, ambivalent attachment, and insecure-controlling/ insecure-other attachment.

\subsubsection{Student- Teacher Relationship Scale (STRS)}

The Student-Teacher Relationship Scale (STRS) was used to assess teacher-child relationship quality at 54 months in preschool. Conflict score was used in this study. "Conflict refers to the extent that the teacher and child are at odds with each other" (Pianta, 1999, p.94)[6]. Pianta (2001) provided evidence for both test-retest and internal consistency reliability[7]. Teachers responded on a 5-option scale that ranges from 1 (definitely does not apply) to 5 (definitely applies).

\subsubsection{Data Analysis}

The demographics variables included child gender, mother's education and income-to needs ratio. The study used dummy coding to code child gender: boys were coded as 1 and girls were coded as 0 . Girls served as the reference group. The study used dummy coding to code mother-child attachment at age 3. Three dummy variables represented avoidant, ambivalent, insecure-controlling/insecure-other attachment at 36 months. Secure attachment served as the reference group. To address the research question, we conducted sequential multiple regressions.

\section{RESULTS}

\subsection{The Effect of Teacher-Child Conflict on Later Behavior Problems}

Results of the sequential multilevel regression analysis regarding the prediction of internalizing problem (54 months) are summarized in Table 1. Teacher-child conflict had a statistically significant effect on the internalizing problems $(\beta=.071, p<.05$; $\Delta \mathrm{R} 2=.005, \mathrm{p}<.05)$.

Table 1. Predicting Internalizing Problems at 54 Months from Teacher-Child Conflict Controlling for Demographic Variables, Early Mother-Child Attachment and Prior Internalizing Problems

\begin{tabular}{|c|c|c|c|c|}
\hline & Model & $\beta$ & SE & $\Delta \mathrm{R} 2$ \\
\hline \multirow{8}{*}{ Block1 } & Constant & & 2.829 & $.284 * * *$ \\
\hline & child gender & -.054 & .572 & \\
\hline & mother's education, & .051 & .140 & \\
\hline & income-to-needs ratio & .006 & .106 & \\
\hline & $\begin{array}{l}\text { prior internalizing } \\
\text { problems }\end{array}$ & $.526 * * *$ & .032 & \\
\hline & avoidant attachment & .022 & 1.414 & \\
\hline & ambivalent attachment & .040 & .806 & \\
\hline & $\begin{array}{l}\text { insecure-controlling/ } \\
\text { insecure-other } \\
\text { attachment }\end{array}$ & .053 & .798 & \\
\hline Block2 & teacher-child conflict & $.071 *$ & .043 & $.005^{*}$ \\
\hline
\end{tabular}

$* \mathrm{p}<.05, * * \mathrm{p}<.01$ and $* * * \mathrm{p}<.001$

Table 2. Predicting Externalizing Problems at 54 Months from Teacher-Child Conflict Controlling for Demographic Variables, Early Mother-Child Attachment and Prior Externalizing Problems

\begin{tabular}{|c|c|c|c|c|}
\hline & Model & $\beta$ & SE & $\Delta \mathrm{R} 2$ \\
\hline \multirow{8}{*}{ Block1 } & Constant & & 2.647 & $.414 * * *$ \\
\hline & child gender & $.092 *$ & .527 & \\
\hline & mother's education & -.003 & .127 & \\
\hline & income-to-needs ratio & -.007 & .098 & \\
\hline & $\begin{array}{l}\text { prior externalizing } \\
\text { problems }\end{array}$ & $.611 * * *$ & .033 & \\
\hline & avoidant attachment & .005 & 1.304 & \\
\hline & $\begin{array}{l}\text { ambivalent } \\
\text { attachment }\end{array}$ & -.025 & .741 & \\
\hline & $\begin{array}{l}\text { insecure-controlling } \\
\text { /insecure-other } \\
\text { attachment }\end{array}$ & -.003 & .737 & \\
\hline Block2 & teacher-child conflict & $.167 * * *$ & .040 & $.027 * * *$ \\
\hline
\end{tabular}

$* \mathrm{p}<.05$ and $* * \mathrm{p}<.01$ 
Results of the sequential multilevel regression analysis regarding the prediction of externalizing problem (54 months) are summarized in Table 2. Teacher-child conflict had a statistically significant effect on externalizing problems $(\beta=.167, \mathrm{p}<.05 ; \Delta$ R2 =.027, p<.001). Higher levels of teacher-child conflict were associated with more externalizing problems.

\subsection{The Moderation Role of Teacher-Child Relationships}

Results of the sequential multilevel regression analysis regarding the prediction of internalizing problem (54 months) are summarized in Table 3. The second block was not statistically significant $(\Delta \mathrm{R} 2=.002, \mathrm{p}>.05)$.

Table 3. Predicting Internalizing Problems at 54 Months from Interaction of Early Mother-Child Attachment and TeacherChild Conflict Controlling for Demographic variables and Prior Internalizing Problems

\begin{tabular}{|c|c|c|c|c|}
\hline Model & Variables & $\beta$ & SE & $\Delta \mathrm{R} 2$ \\
\hline \multirow{9}{*}{ Block1 } & constant & & 2.757 & $.289 * * *$ \\
\hline & child gender & -.053 & .574 & \\
\hline & mother's education & .052 & .140 & \\
\hline & income-to-needs ratio & .005 & .107 & \\
\hline & $\begin{array}{l}\text { prior internalizing } \\
\text { problems }\end{array}$ & $\begin{array}{l}.524 * * \\
* \\
\end{array}$ & .032 & \\
\hline & avoidant attachment & .029 & 1.479 & \\
\hline & $\begin{array}{l}\text { ambivalent } \\
\text { attachment, }\end{array}$ & .043 & .811 & \\
\hline & $\begin{array}{l}\text { insecure-controlling } \\
\text { /insecure-other } \\
\text { attachment }\end{array}$ & .047 & .807 & \\
\hline & conflict(centered) & .063 & .053 & \\
\hline \multirow{4}{*}{ Block2 } & & & & .002 \\
\hline & $\begin{array}{l}\text { avoidant* } \\
\text { conflict(centered) }\end{array}$ & .023 & .314 & \\
\hline & $\begin{array}{l}\text { ambivalent* } \\
\text { conflict(centered) }\end{array}$ & -.021 & .113 & \\
\hline & $\begin{array}{l}\text { insecure-controlling/ } \\
\text { insecure } \quad \text {-other } \\
\text { *conflict (centered) }\end{array}$ & .034 & .119 & \\
\hline
\end{tabular}

$* \mathrm{p}<.05, * * \mathrm{p}<.01$ and $* * * \mathrm{p}<.001$

Results of the sequential multilevel regression analysis regarding the prediction of externalizing problem (54 months) are summarized in Table 4. The second block was not statistically significant $(\Delta \mathrm{R} 2=.002, \mathrm{p}>.05)$.

The impact of attachment type on behavior problems was not moderated by the conflict of the teacher-child relationship.
Table 4. Predicting Externalizing Problems at 54 Months from Interaction of Early Mother-Child Attachment and TeacherChild Conflict Controlling for Demographic Variables and Prior Externalizing Problems

\begin{tabular}{|c|c|c|c|c|}
\hline Model & Variables & $\beta$ & SE & $\Delta \mathrm{R} 2$ \\
\hline \multirow{9}{*}{ Block1 } & constant & & 2.616 & $.440 * * *$ \\
\hline & child gender & $.096 * *$ & .529 & \\
\hline & mother's education, & .001 & .128 & \\
\hline & $\begin{array}{l}\text { income-to-needs } \\
\text { ratio }\end{array}$ & -.011 & .098 & \\
\hline & $\begin{array}{l}\text { prior externalizing } \\
\text { problems }\end{array}$ & $.614 * * *$ & .033 & \\
\hline & avoidant attachment & .018 & 1.364 & \\
\hline & $\begin{array}{l}\text { ambivalent } \\
\text { attachment }\end{array}$ & -.026 & .745 & \\
\hline & $\begin{array}{l}\text { insecure-controlling/ } \\
\text { insecure-other } \\
\text { attachment }\end{array}$ & -.003 & .745 & \\
\hline & conflict(centered) & $.149 * * *$ & .049 & \\
\hline \multirow{4}{*}{ Block2 } & & & & .002 \\
\hline & $\begin{array}{l}\text { avoidant* } \\
\text { conflict(centered) }\end{array}$ & .048 & .290 & \\
\hline & $\begin{array}{l}\text { ambivalent* } \\
\text { conflict(centered) }\end{array}$ & .020 & .104 & \\
\hline & $\begin{array}{l}\text { insecure-controlling } \\
\text { /insecure-other } \\
\text { *conflict(centered) }\end{array}$ & .009 & .110 & \\
\hline
\end{tabular}

$* \mathrm{p}<.05, * * \mathrm{p}<.01$ and $* * * \mathrm{p}<.001$

\section{DISCUSSION}

\subsection{The Effect of Teacher-Child Conflict on Later Behavior Problems}

Children who were rated as having more conflict in their relationships with their teachers were more likely to have both internalizing and externalizing problems. The findings from regression were consistent with the literature that higher teacher-child conflict in preschool predicted children's higher behavior problems (Silver et al., 2005) [8]. Children may learn new behavioral strategies through teacherchild relationships (e.g., Baker, Grant, \& Morlock, 2008) [9]. Teachers may seek more punitive actions for children's inappropriate and noncompliant behavior and have less interaction with children for whom they experience more conflict. Consequently, this conflict teacher-child relationship increases the possibility of children's behavior problems (Myers \& Pianta, 2008) [10].

\subsection{The Moderation Role of Teacher-Child Conflict}

The finding of this study was not in accordance with the literature (Buyse et al., 2011) [1]. There are several possible explanations to the lack of interaction effects. First, the measurement of attachment in this study was different from that of the Buyse et al.'s study. This study used a Modified 
Strange Situation Procedure to assess mother-child attachment, which is a categorical scale of measurement; the study of Buyse et al. used AQS, which results in a continuous scale of measurement of attachment. Secondly, this study examined the moderation effect after controlling for child gender, mother's education, family SES, and more important, prior behavior problems. However, Buyse et al. examined the moderation effect after only controlling for child gender. The results of their study found there was a large effect of attachment on children's behavior problems. Thirdly, as previously mentioned, the NICHD sample is relatively low risk. It is possible that moderation effects may have been revealed in a sample with more variance.

\subsection{Suggestions for Further Research}

The goal of this study was to examine the moderation effects of teacher-child conflict in association with early mother-child attachment and later behavior problems. There are two suggestions for future research in this study. The first suggestion is to consider other children's outcomes, such as social skills or academic achievement. To date, there is a significant amount of research that has been conducted that shows positive student-teacher relationships can benefit children. Considering the extensive literature that demonstrates how these relationships can increase children's social skills and academic achievement, it can be expected that other positive outcomes may also be associated with positive teacher relationships. Teacher-child conflict did not evidence a moderation role in linking early mother-child attachment and behavior problems in preschool. This does not imply, however, that the quality of teacher-child relationships does not contribute to children's behavior problems. Early mother-child attachment has been demonstrated in other studies to have an impact on teacher-child relationships, but the quality of the relationship that a child forms with a person is the result of the interplay between representations based on past relationships, as well as of characteristics of the current relationship partner, in this case the teacher (Zajac \& Kobak, 2006)[11]. Thus, the second suggestion for future research may wish to consider aspects of the teacher, such as her mental representation of attachment, or the classroom context (e.g., whether it has a positive or negative climate).

\section{REFERENCES}

[1] Buyse, E., Verschueren, K., \& Doumen, S. (2011). Preschoolers' attachment to mother and risk for adjustment problems in kindergarten: Can teachers make a difference? Social Development, 20(1), 33-50.

[2] NICHD Early Child Care Research Network. (1997). The effects of infant child care on infant-mother attachment securing: Results of the NICHD Study of Early Child Care. Child Development, 68, 860-879.

[3] Achenbach, T. M. (1991). Manual for the Child Behavior Checklist/4-18 and 1991Profile.Burlington, VT: Department of Psychiatry, University of Vermont.

[4] Achenbach, T. M. (1992). Manual for the Child Behavior Checklist /2-3 and 1992 Profile. Burlington, VT: Department of Psychiatry, University of Vermont.

[5] Cassidy, J., \& Marvin, R. S., with the MacArthur Attachment Working Group. (1992). Attachment organization in preschool children: Coding guidelines (4th ed.). Unpublished manuscript, University of Virginia. MacArthur Working Group on Attachment, Seattle, WA.

[6] Pianta, R. C. (1999). Enhancing relationships between children and teachers.Washington, DC, US: American Psychological Association

[7] Pianta, R. C. (2001). STRS Student-Teacher Relationship Scale. Professional manual. Odessa, FL: Psychological Assessment Resources.

[8] Silver, R. B., Measelle, J., Armstrong, J. M., \& Essex, M. J. (2005). Trajectories of classroom externalizing behavior: Contributions of child characteristics, family characteristics, and the teacher-child relationships during the school transition. Journal of School Psychology, 43(1), 39-60.

[9] Baker, J. A., Grant, S., \& Morlock, L. (2008).The teacherstudent relationship as a developmental context for children with internalizing or externalizing behavior problems. School Psychology Quarterly, 23(1), 3-15.

[10] Myers, S. S., \& Pianta, R. C. (2008). Developmental commentary: Individual and contextual influences on student-teacher relationships and children's early problem behaviors. Journal of Clinical Child and Adolescent Psychology, 37(3), 600-608.

[11] Zajac, K., \& Kobak, R. (2006). Attachment. In G. G. Bear, \& K. M. Minke (Eds.), Children's needs III: Development, prevention and intervention (pp. 379-389). Washington, DC: National Association of School Psychologists. 